\title{
Strain evolution during spinodal decomposition of TiAlN thin films
}

Lina Rogström, Jennifer Ullbrand, J. Almer, Lars Hultman, B. Jansson and Magnus Odén

\section{Linköping University Post Print}

N.B.: When citing this work, cite the original article.

Original Publication:

Lina Rogström, Jennifer Ullbrand, J. Almer, Lars Hultman, B. Jansson and Magnus Odén, Strain evolution during spinodal decomposition of TiAlN thin films, 2012, Thin Solid Films, (520), 17, 5542-5549.

http://dx.doi.org/10.1016/j.tsf.2012.04.059

Copyright: Elsevier

http://www.elsevier.com/

Postprint available at: Linköping University Electronic Press

http://urn.kb.se/resolve?urn=urn:nbn:se:liu:diva-75174 


\title{
Strain evolution during spinodal decomposition of TiAlN thin films
}

\author{
L. Rogström, a, , J. Ullbrand ${ }^{\mathrm{a}}$, J. Almer ${ }^{\mathrm{b}}$, L. Hultman ${ }^{\mathrm{c}}$, B. Jansson ${ }^{\mathrm{a}, \mathrm{d}}$, and M. Odén ${ }^{\mathrm{a}}$
}

a. Nanostructured Materials, Dept. Physics, Chemistry and Biology (IFM), Linköping University, 58183 Linköping, Sweden

b. Advanced Photon Source, Argonne National Laboratory, Argonne, IL 60439 USA

c. Thin Film Physics, Dept. Physics, Chemistry and Biology (IFM), Linköping University, 58183 Linköping, Sweden

d. Seco Tools AB, 73782 Fagersta, Sweden

* Corresponding author: linro@ifm.liu.se

\section{$\underline{\text { Abstract }}$}

We use a combination of in-situ x-ray scattering experiments during annealing and phasefield simulations to study the strain and microstructure evolution during decomposition of TiAlN thin films. The evolved microstructure is observed to depend on the initial alloy composition, where the larger elastic anisotropy of higher Al content films causes formation of elongated AlN and TiN domains. The simulations show strain formation in the evolving cubic AlN and TiN domains, which is a combined effect of increasing lattice mismatch and elastic incompatibility between the domains. The experimental results show that the strain of the film is a result of defect density, thermal strains, and the phase evolution during decomposition of the cubic TiAlN. The compressive strain increases at temperatures above $\sim 850{ }^{\circ} \mathrm{C}$ for $\operatorname{Ti}_{0.35} \mathrm{Al}_{0.65} \mathrm{~N}$ and above $\sim 930{ }^{\circ} \mathrm{C}$ for $\mathrm{Ti}_{0.53} \mathrm{Al}_{0.47} \mathrm{~N}$ due to the onset of transformation to hexagonal-AlN, which is similar to the temperature where the maximum hardness of similar TiAlN films has been found. The higher driving force for decomposition in the higher $\mathrm{Al}$ content film results in a higher decomposition rate revealed by the simulations and earlier formation of hexagonal-AlN in this film. 
Keywords: Ti-Al-N, Thin film, Phase-field simulations, Spinodal decomposition, High energy $\mathrm{x}$-ray diffraction 


\section{$\underline{\text { 1. Introduction }}$}

TiAlN is one of the most studied ternary transition metal nitrides systems. The metastable cubic structure is known to decompose during annealing into its equilibrium phases cubic (c) TiN and hexagonal ( $h$ ) AlN. It was early observed that the system exhibits age hardening when annealed due to the decomposition of the solid solution into $c$-TiN-rich and $c$-AlN-rich regions [1-3]. Ab-initio calculations show that the system exhibits a miscibility gap $[4,5]$ and the decomposition is thus considered to be of the spinodal type. Knutsson et al. [3] observed that after annealing of TiAlN, coherent regions enriched in $c$-TiN and $c$-AlN are formed. The coherency strains formed act as barriers for dislocation motion contributing to the age hardening. Also the difference in elastic properties between domains of different composition will enhance the mechanical properties, similar to what was predicted by Koehler for materials consisting of phases with different shear modulus [6]. Tasnadi et al. showed that there is a significant change in the elastic properties of TiAlN when the $\mathrm{Al}$ content is changed [7].

The elastic properties are also important for the microstructure evolution during spinodal decomposition, as was shown by Cahn [8]. Further, phase field simulations by Seol et al. [9] showed that the microstructure in a thin film will depend on the elastic anisotropy of the material. They also observed that the coherency strains formed during decomposition can influence the microstructure. However, there is a lack of knowledge on how the evolving strains arise and its influence on the decomposition process.

In this study, we use in-situ high energy x-ray diffraction (XRD) experiments to study both the strain and microstructure evolution during decomposition. In addition, we use simulations based on the phase-field method of the strain and microstructure evolution to 
establish and separate different effects contributing to the strain evolution during annealing.

The phase field approach used here is based on a description of Gibbs free energy using ideal mixing of the entropy and enthalpy of mixing collected from the literature [10] together with a modified Cahn-Hilliard [11] time dependent partial differential equation to predict the microstructure evolution over time for different alloy compositions. We also include an elastic energy term that takes into account the influence of elastic properties and anisotropy [7], and the non-linear lattice parameter dependency on alloy composition of this system $[5,12]$

The high energy in-situ XRD experiments were performed during annealing of arcevaporated TiAlN thin films in transmission geometry. Such set up allows for phase specific strain data collection [13]. As the full diffraction rings can be used in the analysis, the strain in both in-plane and the film growth direction are recorded. Since the exposure time required is of the order of $30 \mathrm{~s}$, time-resolved experiments can be performed, which enabled us to study the strain evolution during phase decomposition of these films.

Strain contributions arising during annealing from the decomposition process and those arising from defect annihilation and other processes are distinguished by comparing experimental and theoretical results. 


\section{$\underline{\text { 2. Experimental details }}$}

TiAlN films were deposited using an industrial scale arc-evaporation system. TiAl alloy cathodes were evaporated in a $\mathrm{N}_{2}$ reactive gas at a temperature of $\sim 500{ }^{\circ} \mathrm{C}$. Substrates were mounted on a drum that rotates during deposition and a negative bias was applied to the substrates.

For in-situ diffractometry experiments substrates of polished WC-Co were used and depositions were made with two different cathode compositions $\left(\mathrm{Ti}_{0.50} \mathrm{Al}_{0.50}\right.$ and $\left.\operatorname{Ti}_{0.33} \mathrm{Al}_{0.67}\right)$. For each composition, samples with low bias $(20 \mathrm{~V})$ and high bias (40 or 60 V) were deposited. After deposition, the substrates were cut into $1 \mathrm{~mm}$ thick cross sectional slices. Fractured cross sections were studied in a LEO 1550 FEG scanning electron microscope (SEM). The metal composition of the as-deposited films was determined by energy dispersive x-ray spectroscopy (EDS) in the SEM. Mechanically polished and ion-milled cross sections of an as-deposited sample and a sample, postdeposition annealed for 2 hours at $900{ }^{\circ} \mathrm{C}$, was studied by (scanning) transmission electron microscopy ((S)TEM) using a FEI Technai G2 instrument.

Thin films with three different compositions (using $\mathrm{Ti}_{0.75} \mathrm{Al}_{0.25}, \mathrm{Ti}_{0.50} \mathrm{Al}_{0.50}$ and $\mathrm{Ti}_{0.33} \mathrm{Al}_{0.67}$ cathodes, respectively) were deposited onto Fe-foils, using the same deposition parameters and with a bias of $20 \mathrm{~V}$, for powder diffraction and thermal analysis experiments. The films were detached from their substrates through substrate etching in hydrochloride acid. The remaining film was cleaned in de-ionized water, ground to a fine powder and placed in a plastic container.

Thermal analysis was performed using a Netzsch STA 449 F3 Jupiter differential scanning calorimeter (DSC). The heat flux was recorded during a heating cycle from 
room temperature to $1410{ }^{\circ} \mathrm{C}$ and back to room temperature with a constant heating rate of $20^{\circ} \mathrm{C} / \mathrm{min}$ in an Ar atmosphere. A second cycle was made immediately after the first to serve as base line correction.

X-ray scattering experiments were performed at beamline 1-ID at the Advanced Photon Source (APS) at Argonne National Laboratory. For in-situ experiments, a sample cut to 1 $\mathrm{mm}$ thickness was placed with the growth direction parallel to the vertical direction as schematically shown in fig. 1 . The sample was mounted in a tungsten holder to ensure even sample heating and the holder was placed inside a vacuum furnace. The pressure in the furnace was below $5 \cdot 10^{-3}$ Torr during measurement and the samples were heated with a constant rate of $5{ }^{\circ} \mathrm{C} / \mathrm{min}$. An area detector (GE Angio) with $200 \times 200 \mu \mathrm{m}^{2}$ pixels was placed downstream from the sample. Exposures were taken every $13^{\text {th }}$ second, each exposure consisting of ten summed $1 \mathrm{~s}$ snap shots. For powder diffraction measurements, the plastic holder containing the powder was placed in the beam at $1304 \mathrm{~mm}$ from the detector. Exposures consisting of 5 summed 1s snap shots were taken for each sample. The sample-to-detector distance was calibrated using a NIST reference material (CeO powder) for both types of experiment. The accuracy of the lattice parameter as determined by powder diffraction is determined by the uncertainty of sample positioning relative to the $\mathrm{CeO}$ powder $(\sim \pm 0.1 \mathrm{~mm})$ and the accuracy of the $\mathrm{CeO}$ lattice parameter (5.4111 ̊).

The two-dimensional diffraction patterns were transformed to 72 one-dimensional patterns using azimuthal bins of $5^{\circ}$ each. Pseudo-Voigt functions were fitted to the diffraction peaks of the one-dimensional patterns to extract lattice spacings $(d)$ and full width at half maximum (fwhm) for each azimuthal bin and for all diffraction peaks. 


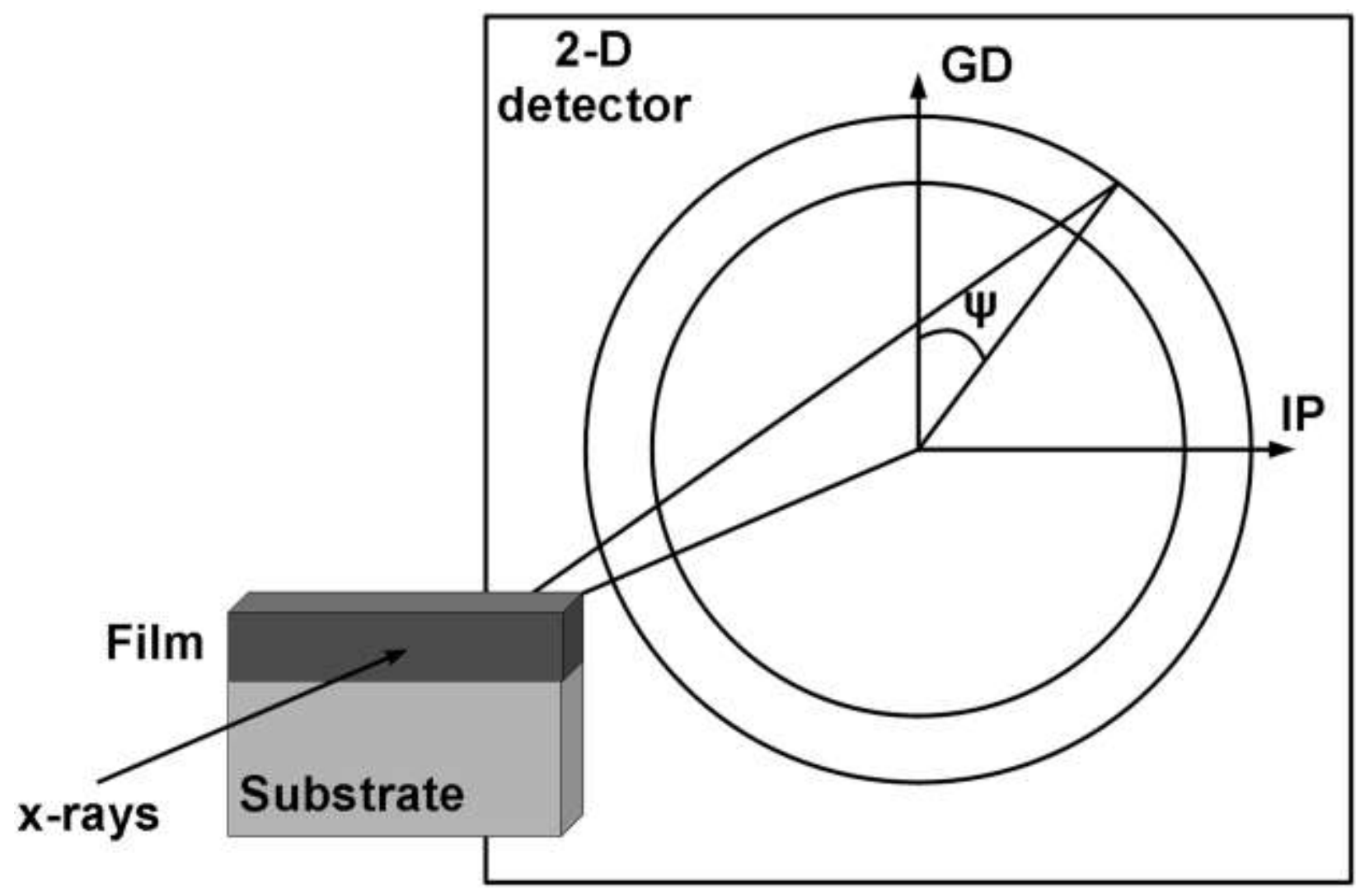

Figure 1: Schematic of the experimental setup for in-situ x-ray scattering showing the tilt angle, $\psi$, and the film in-plane (IP) and growth (GD) directions.

For the powder samples, the peak positions were determined for each azimuthal bin and the mean value was calculated. The mean peak position was then recalculated to lattice parameters, $a_{0}^{h k l}$, for the (111), (200), and (220) planes. The average value of the three lattice parameters $\left(a_{0}^{111}, a_{0}^{200}\right.$ and $\left.a_{0}^{220}\right)$ was calculated and is reported here. The radial strain in the films was determined by $\varepsilon_{\psi}=\left(d_{\psi}-d_{0}\right) / d_{0}$ where $d_{0}$ is the strain-free lattice spacing and $d_{\psi}$ is the lattice spacing at tilt angle $\psi$, see figure 1 . The strain-free lattice spacing was obtained from the powder diffraction, and corrected for thermal expansion during the in-situ measurements. The strain reported here is the strain in the film in-plane 
(IP), $\psi=\left[80: 100^{\circ}\right]$, direction and for the peak width the mean value for all azimuths is shown.

\section{Simulations}

A continuous phase field approach in two dimensions is used where TiAlN is approximated as a pseudo-binary system consisting of TiN and AlN. The nitrogen content is homogenous throughout of the simulation box and the model only accounts for substitution diffusion of $\mathrm{Ti}$ and $\mathrm{Al}$ on the metal lattice. A 50 x $50 \mathrm{~nm}^{2}$ two-dimensional box with approximately 100000 nodes in a triangular mesh is used to simulate the microstructure evolution in the [00-1]-direction. An initial fluctuation of the composition is imposed to start the decomposition, i.e. to mimic the effect of randomly occurring compositional variations due to thermal fluctuations in a real sample. As the compositional fluctuations in the box are randomized they will not influence the resulting microstructure evolving during decomposition.

For each node, the phase field variables are solved for each time step. The driving force for decomposition is the minimization of the systems Gibb's free energy, $\Delta G$, where the difference compared to the pure TiN and AlN is given by

$$
\Delta G=\frac{1}{V_{m}}\left(\int_{\Omega} \Delta G_{m}\left(x_{k}\right)-\kappa\left|\nabla x_{k}\right|^{2}+\Delta E_{e l, m}\right) d \Omega .
$$

Here, $x_{k}$ is the molar fraction of element $k, G_{m}$ is the free energy of mixing per mole for a homogeneous system, $\kappa$ is the gradient energy coefficient, and $E_{e l, m}$ is the elastic energy per mole and the integration is performed over the whole volume, $\Omega$. The different terms of eq. (1) are described in more detail below. The molar volume, $V_{m}$, is considered to be a 
constant and equal to $1.076 \times 10^{-5} \mathrm{~m}^{3}$ based on calculations for a face centered cubic structure with a lattice parameter of $4.15 \AA\left(\mathrm{Ti}_{0.33} \mathrm{Al}_{0.67} \mathrm{~N}\right)[5,12]$.

Using the modified Cahn-Hilliard equation [11]

$$
\frac{\partial x_{k}}{\partial t}=\nabla\left(M^{\prime} \nabla\left(\frac{\partial G_{m}}{\partial x_{k}}-2 \kappa \nabla^{2} x_{k}+\frac{\partial E_{e l, m}}{\partial x_{k}}\right)\right),
$$

the variation of composition in space and time is calculated. The $M^{\prime}$-parameter is related to the mobility, $M$, of the diffusing species, for a dilute solution, as

$$
M^{\prime}=x_{A} x_{B} \cdot\left(x_{B} M_{A}+x_{A} M_{B}\right)=x_{A} x_{B} \cdot\left(x_{A} D_{B}+x_{B} D_{A}\right) / R T,
$$

where $A$ and $B$ denotes the two elements ( $\mathrm{Ti}$ and $\mathrm{Al}$ ), $T$ is the temperature and $R$ is the molar gas constant. The mobility depends on the self diffusivities, $D_{k}$, which in this case are assumed to be equal and constant for Ti and $\mathrm{Al}$ so that $D_{A}=D_{B}=10^{-19} \mathrm{~m}^{2} / \mathrm{s}$ at $900{ }^{\circ} \mathrm{C}$. There are three contributions to the driving force in the Cahn-Hilliard equation, eq. (2). The first term is the free energy of mixing,

$$
\Delta G_{m}\left(x_{k}\right)=\Delta G_{m i x}=\Delta H_{m i x}-T \Delta S_{m i x},
$$

where the enthalpy of mixing, $\Delta H_{m i x}$, is assumed to take the form of a Redlich-Kister polynomial, $L_{n}$, to the order of $n=3$,

$$
\Delta H_{m i x}=x_{A} x_{B} \sum_{i=0}^{n}\left(x_{A}-x_{B}\right)^{n} \cdot L_{n} .
$$

The $L_{n}$ constants are fitted to DFT data [10].

The entropy of mixing, $\Delta S_{m i x}$, is, assuming ideal mixing, given by,

$$
\Delta S_{\text {mix }}=-R\left(x_{A} \ln x_{A}+x_{B} \ln x_{B}\right) .
$$


The second term in eq. (2) is the gradient energy and is described in the same manner as Cahn-Hilliard did [11] i.e. distributing the enthalpy of mixing on the nearest neighbor bonds,

$$
\kappa=\frac{b^{2}}{2} \sum_{i=0}^{n}\left(x_{A}-x_{B}\right)^{n} \cdot L_{n},
$$

where $b$ is the interatomic distance.

The third term of eq. (2) is the contribution from elastic energy where the difference in elastic energy is taken as

$$
\Delta E_{e l, m}=\frac{1}{2}\left(\sigma_{x}\left(\varepsilon_{x}-\varepsilon_{m}\right)+\sigma_{y}\left(\varepsilon_{y}-\varepsilon_{m}\right)+\sigma_{x y} \varepsilon_{x y}\right) \cdot V_{m}
$$

where the stress, $\sigma_{i j}$ for a cubic crystal is

$$
\begin{aligned}
& \sigma_{x}=C_{11} \varepsilon_{x}+C_{12} \varepsilon_{y}-\left(C_{11}+2 C_{12}\right) \varepsilon_{m} \\
& \sigma_{y}=C_{11} \varepsilon_{y}+C_{12} \varepsilon_{x}-\left(C_{11}+2 C_{12}\right) \varepsilon_{m} \\
& \sigma_{x y}=C_{44} \varepsilon_{x y} .
\end{aligned}
$$

The stress is calculated using elastic stiffness constants, $C_{i j}\left(x_{A}\right)$, for TiAlN dependent of the composition as calculated from DFT [7]. $\varepsilon_{m}$ is the so called eigenstrain, i.e. the relaxed strain relative to the relaxed strain of the initial state. The eigenstrain, $\varepsilon_{m}$, is given by the difference in stress-free (relaxed) lattice parameter for a specific composition, $a_{r}$, relative to $\boldsymbol{a}_{r}^{\text {initial }}$,

$$
\varepsilon_{m}=\left(a_{r}-a_{r}^{\text {initial }}\right) / a_{r}^{\text {initial }},
$$

where $a_{r}^{\text {initial }}$ is the stress-free (relaxed) lattice parameter of the initial composition. The relaxed lattice parameter is obtained by a fitted cubic polynomial function to DFT data [5, 12]. The strain in $x$ and $y$ directions relative to the initial conditions is 


$$
\begin{aligned}
& \varepsilon_{x}=\frac{\partial u}{\partial x} \\
& \varepsilon_{y}=\frac{\partial v}{\partial y} \\
& \varepsilon_{x y}=\frac{\partial u}{\partial y}+\frac{\partial v}{\partial x},
\end{aligned}
$$

where $u$ and $v$ are displacement vectors in $x$ and $y$ direction respectively. The elastic strain in eq. (8) is taken as the difference between the actual strain and the unconstrained coherency misfit. The eigenstrain is not contributing to shear strains.

The simulations are performed at $900{ }^{\circ} \mathrm{C}$ and boundary conditions are set such that no forces are acting on the simulation box,

$$
\begin{aligned}
& \frac{\partial \sigma_{x}}{\partial x}+\frac{\partial \sigma_{x y}}{\partial y}=0 \\
& \frac{\partial \sigma_{y}}{\partial y}+\frac{\partial \sigma_{x y}}{\partial x}=0 .
\end{aligned}
$$

The elastic energy term is solved exactly. The partial differential equations, eqns. (2) and (12), are solved using the commercial software Flex PDE [14].

For comparison with experimental data, constant strains are set on the boundaries with values from the experimental results in the film in-plane $(x)$ and growth $(y)$ direction, the values are found in table 1 below. The microstructure is plotted for several time steps in the [00-1]-direction for different compositions to compare with the experimental data. The strain in the $x$ and $y$ directions, corresponding to the experimental film in-plane and growth direction, is calculated as

$$
\begin{aligned}
& \varepsilon_{I P}=\left(\varepsilon_{x}-\varepsilon_{m}\right) /\left(1+\varepsilon_{m}\right)=\left(a_{I P}-a_{r}\right) / a_{r} \\
& \varepsilon_{G D}=\left(\varepsilon_{y}-\varepsilon_{m}\right) /\left(1+\varepsilon_{m}\right)=\left(a_{G D}-a_{r}\right) / a_{r} .
\end{aligned}
$$


Here, $a_{I P}$ and $a_{G D}$ is the lattice parameter in the in-plane and growth direction ( $x$ and $y$ direction), respectively, and $a_{r}$ is as before the relaxed lattice parameter obtained from ab-initio calculations $[5,12]$.

Table 1: Strain determined from the in-situ x-ray diffraction measurements at $500{ }^{\circ} \mathrm{C}$. The corresponding stress is calculated using elastic constants from ref. [7]. The $\varepsilon_{200}$ values for $\mathrm{Ti}_{0.53} \mathrm{Al}_{0.47} \mathrm{~N}(20 \mathrm{~V})$ and $\mathrm{Ti}_{0.35} \mathrm{Al}_{0.65} \mathrm{~N}(20 \mathrm{~V})$ were used as boundary conditions in the simulations.

\begin{tabular}{|c|c|c|c|c|c|c|}
\hline Sample (bias) & $\varepsilon_{200}{ }^{I P}$ & $\varepsilon_{111}{ }^{I P}$ & $\begin{array}{l}\mathrm{E}_{200} \\
(\mathrm{GPa})\end{array}$ & $\begin{array}{l}\mathrm{E}_{111} \\
(\mathrm{GPa})\end{array}$ & $\sigma_{200}(\mathrm{GPa})$ & $\sigma_{111}(\mathrm{GPa})$ \\
\hline $\mathrm{Ti}_{0.53} \mathrm{Al}_{0.47} \mathrm{~N}(20 \mathrm{~V})$ & $\begin{array}{l}-0.00445 \\
9.46 \times 10^{-5}\end{array}$ & $\begin{array}{ll}-0.00298 & \pm \\
6.34 \times 10^{-5}\end{array}$ & 386 & 489 & $-1.72 \pm 0.039$ & $-1.46 \pm 0.034$ \\
\hline $\mathrm{Ti}_{0.53} \mathrm{Al}_{0.47} \mathrm{~N}(40 \mathrm{~V})$ & $\begin{array}{ll}-0.00597 \\
5.69 \times 10^{-4}\end{array}$ & $\begin{array}{l}-0.00482 \quad \pm \\
2.82 \times 10^{-4}\end{array}$ & 386 & 489 & $-2.30 \pm 0.22$ & $-2.36 \pm 0.14$ \\
\hline $\mathrm{Ti}_{0.35} \mathrm{Al}_{0.65} \mathrm{~N}(20 \mathrm{~V})$ & $\begin{array}{l}-0.00338 \\
1.06 \times 10^{-5}\end{array}$ & $\begin{array}{ll}-0.00189 \\
7.02 \times 10^{-5}\end{array}$ & 359 & 515 & $-1.21 \pm 0.0072$ & $-0.97 \pm 0.039$ \\
\hline $\mathrm{Ti}_{0.35} \mathrm{Al}_{0.65} \mathrm{~N}(60 \mathrm{~V})$ & $\begin{array}{l}-0.00939 \\
3.08 \times 10^{-4}\end{array}$ & $\begin{array}{l}-0.00670 \\
7.92 \times 10^{-5}\end{array}$ & 359 & 515 & $-3.37 \pm 0.11$ & $-3.45 \pm 0.041$ \\
\hline
\end{tabular}

The strain is determined for three composition intervals, comparable to the experimentally measured strain in TiAlN, TiN, and AlN. The intervals were set to 0-20\% AlN in TiN, 20-80 \% AlN in TiAlN and 80-100 \% AlN in AlN. In each composition interval the mean strain is calculated and plotted against time. 


\section{Results}

The metal composition of the $\mathrm{Ti}_{1-\mathrm{x}} \mathrm{Al}_{\mathrm{x}} \mathrm{N}$ films as determined by EDS is $\mathrm{x}=0.24, \mathrm{x}=0.47$ and $\mathrm{x}=0.65$ when using $\mathrm{Ti}_{0.75} \mathrm{Al}_{0.25}, \mathrm{Ti}_{0.50} \mathrm{Al}_{0.50}$, and $\mathrm{Ti}_{0.33} \mathrm{Al}_{0.67}$ cathodes, respectively. The slightly lower $\mathrm{Al}$ content in the film compared to the cathode is due to preferential resputtering of the lighter $\mathrm{Al}$ atoms during deposition [15]. Figure 2 shows the lattice parameter determined for the three compositions together with the lattice parameter of arc-evaporated TiN deposited under similar conditions [13] and the lattice parameter determined by ab-initio calculations from ref $[5,12]$. The calculated lattice parameters are observed to deviate from the linear Vegard's law and the same trend can be observed for the experimental results. Similar observations have been made by Mayrhofer et al. [16].

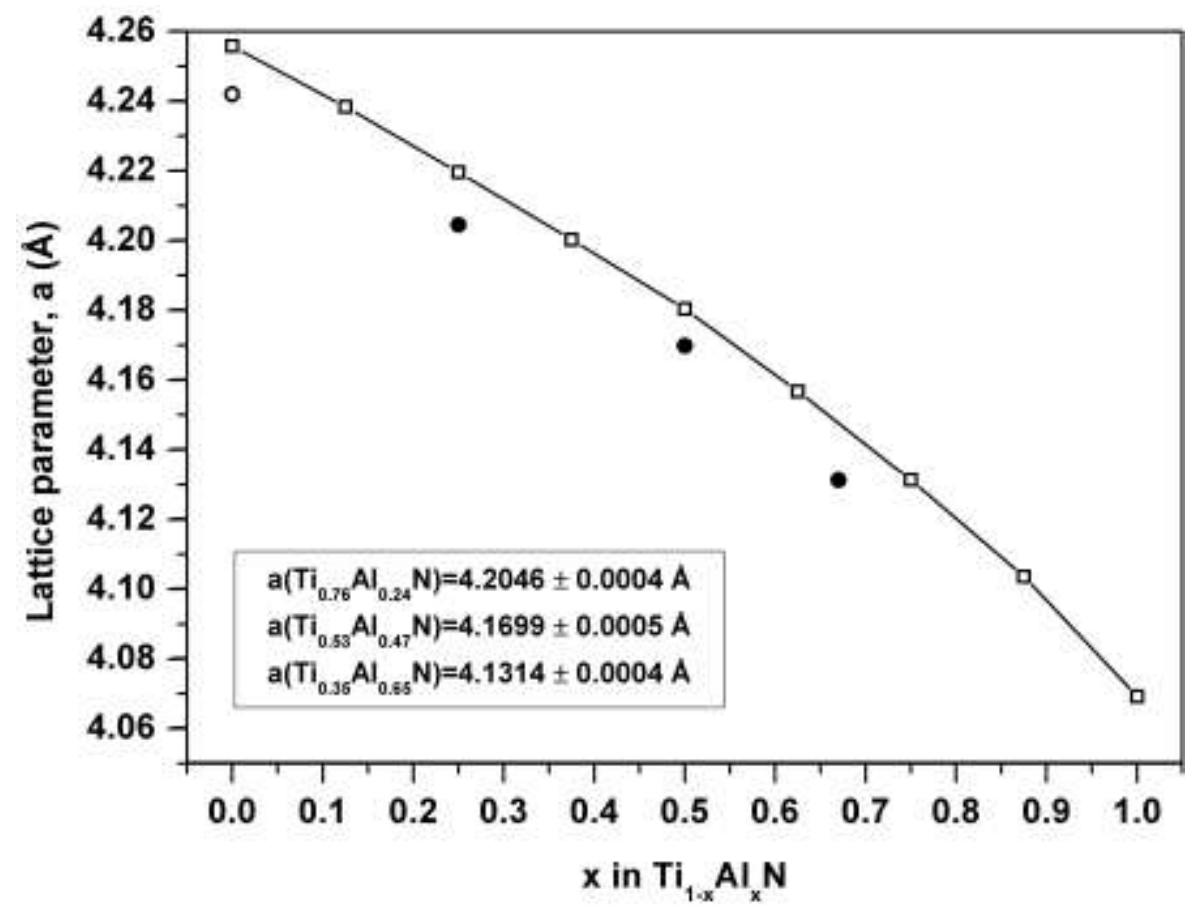

Figure 2: Lattice parameter as determined experimentally (circles) and from ab-initio calculations (line + squares) $[5,12]$. Filled circles are from powder diffraction within this work, the value for TiN is taken from ref. [13]. The error bars of the experimental data are smaller than the symbols. 
The as-deposited films have a dense and columnar structure and a thickness between 5 and $9 \mu \mathrm{m}$ as determined from fractured cross sections studied in the SEM (not shown). Figure 3 (a) shows a TEM micrograph of the as-deposited $\mathrm{Ti}_{0.53} \mathrm{Al}_{0.47} \mathrm{~N}$ film in which the film is observed to have a defect rich columnar structure. Figure 3 (b) shows a STEM micrograph of the same film annealed for $10 \mathrm{~min}$ at $1000{ }^{\circ} \mathrm{C}$. Bright and dark regions are observed, the contrast arising from varying composition due to separation into TiN-and AlN-rich domains.

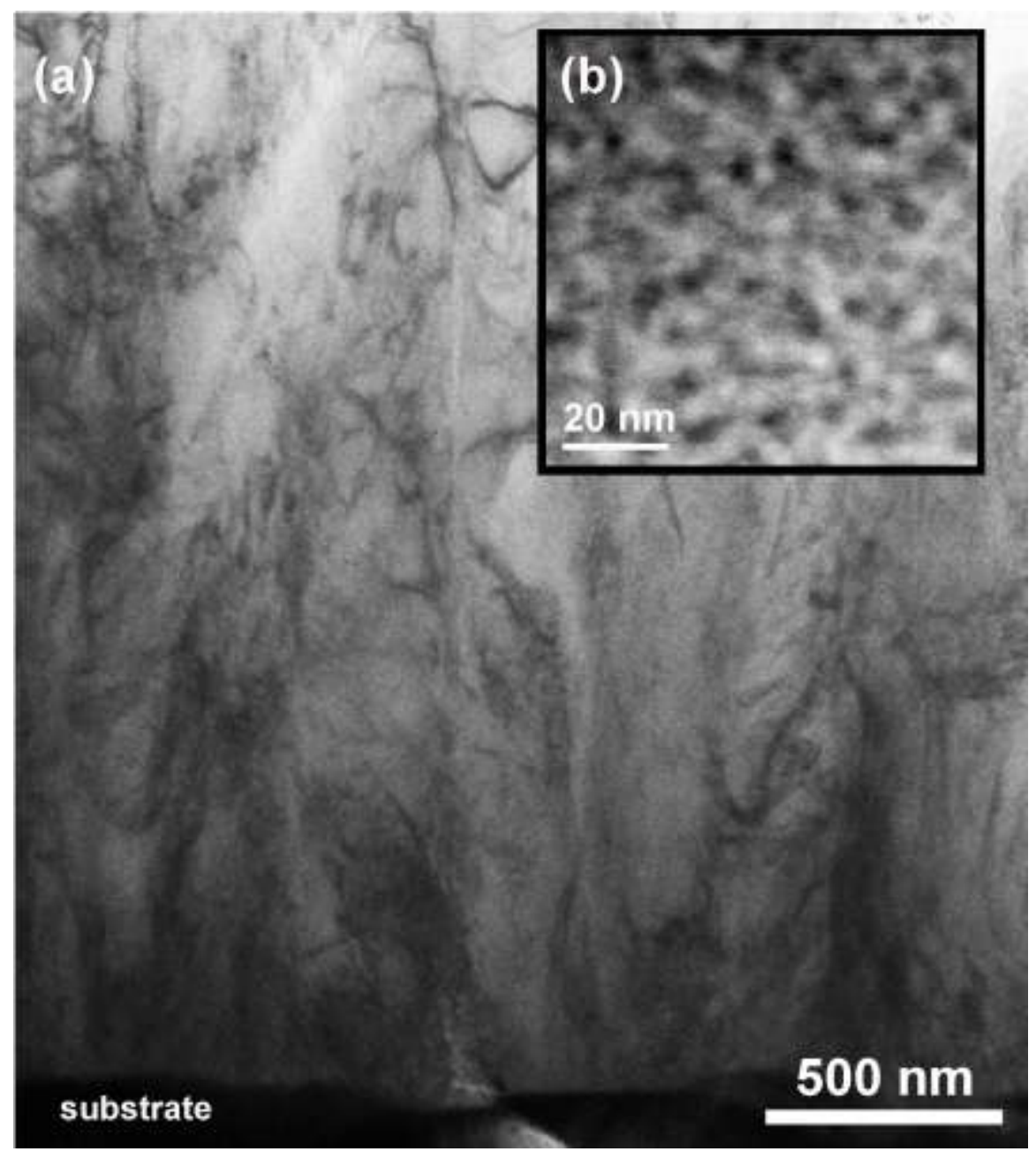

Figure 3: (a) Bright field TEM micrograph of the as-deposited $\mathrm{Ti}_{0.53} \mathrm{Al}_{0.47} \mathrm{~N}$ (20 V) film and (b) elemental contrast STEM micrograph of a $\mathrm{Ti}_{0.53} \mathrm{Al}_{0.47} \mathrm{~N}(20 \mathrm{~V})$ thin film annealed for $10 \mathrm{~min}$ at $1000{ }^{\circ} \mathrm{C}$. 
Figure 4 shows the heat flow as determined by DSC for $\operatorname{Ti}_{0.53} \mathrm{Al}_{0.47} \mathrm{~N}$ and $\operatorname{Ti}_{0.35} \mathrm{Al}_{0.65} \mathrm{~N}$. The peak labeled $\mathrm{T} 1$ probably consists of more than one peak and it starts at temperatures below the deposition temperature. The second peak, labeled $\mathrm{T} 2$, has a maximum at around $850{ }^{\circ} \mathrm{C}$ for the high $\mathrm{Al}$ content films and around $1000{ }^{\circ} \mathrm{C}$ for the lower $\mathrm{Al}$ content. Also the third peak, labeled T3, occurs at higher temperature for the lower Al content. The peak has a maximum around $1100{ }^{\circ} \mathrm{C}$ for $\mathrm{Ti}_{0.35} \mathrm{Al}_{0.65} \mathrm{~N}$ and around $1200{ }^{\circ} \mathrm{C}$ for $\mathrm{Ti}_{0.53} \mathrm{Al}_{0.47} \mathrm{~N}$. All three peaks have similar positions for the low and high bias $\mathrm{Ti}_{0.35} \mathrm{Al}_{0.65} \mathrm{~N}$ film.

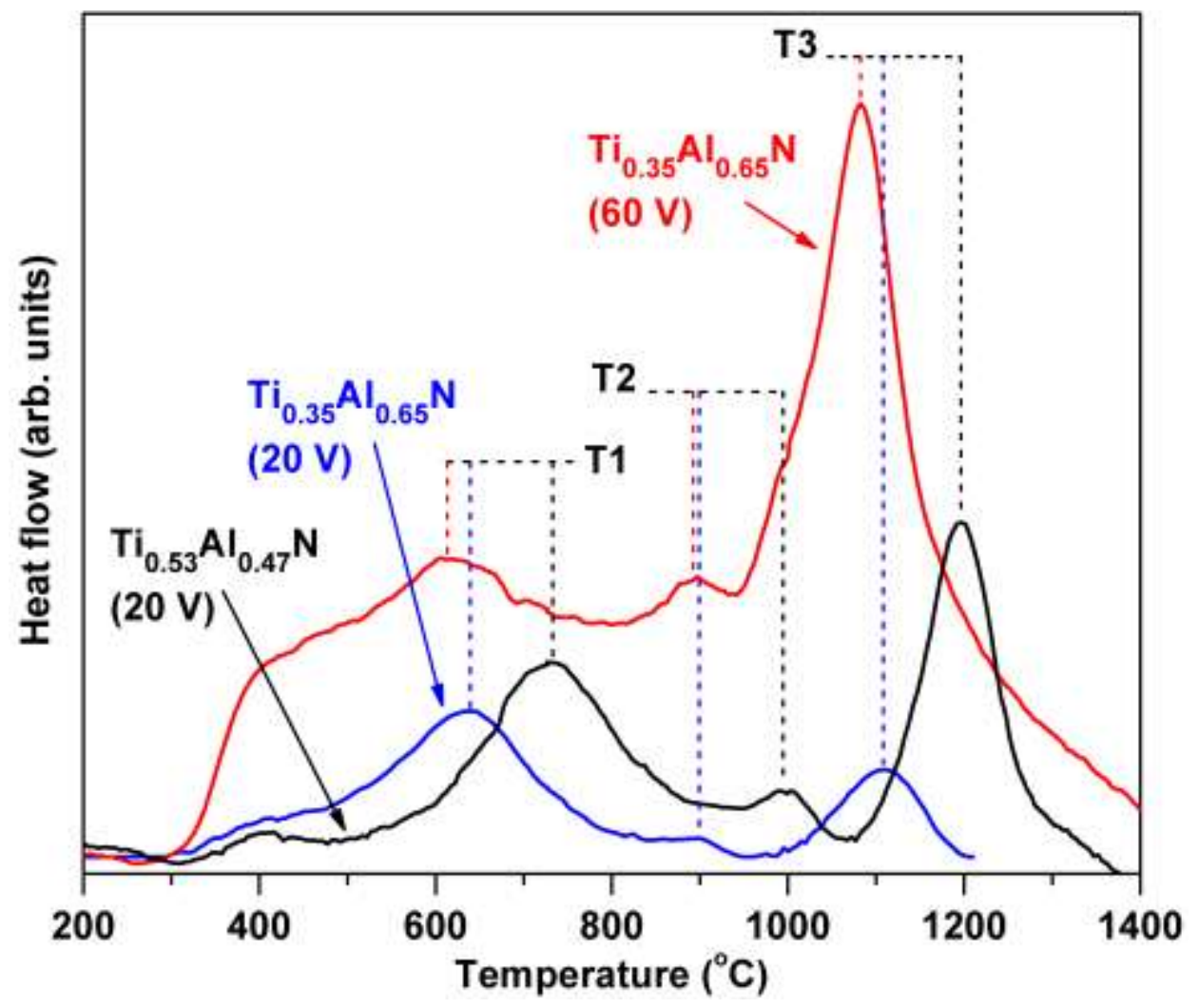

Figure 4: Heat flow of $\mathrm{Ti}_{0.53} \mathrm{Al}_{0.47} \mathrm{~N}$ and $\mathrm{Ti}_{0.35} \mathrm{Al}_{0.65} \mathrm{~N}(20 \mathrm{~V})$ and $\mathrm{Ti}_{0.35} \mathrm{Al}_{0.65} \mathrm{~N}(60 \mathrm{~V})$ thin films (color online). 
Figure 5 (a) and (b) show one-dimensional lineouts from the in-plane direction $(\psi=$ [80:100 $\left.{ }^{\circ}\right]$ of the $\mathrm{Ti}_{0.53} \mathrm{Al}_{0.47} \mathrm{~N}$ and $\mathrm{Ti}_{0.35} \mathrm{Al}_{0.65} \mathrm{~N}$ films, respectively, deposited with low $(20 \mathrm{~V})$ bias. The diffractogram at the top of the figures shows the as-deposited film and the other are diffractograms recorded at an elevated temperature $\left(T_{a}\right)$ between 850 and $1150{ }^{\circ} \mathrm{C}$ with a temperature interval of $\sim 10{ }^{\circ} \mathrm{C}$. No diffraction peaks other than $c$-TiAlN and peaks originating from the substrate are observed for the as-deposited films. At around $950{ }^{\circ} \mathrm{C}$, for both compositions, a shoulder is observed at the right-hand side of the $c$-TiAlN peaks corresponding to $c$-TiN. As the temperature is increased further, the intensity of the TiN peaks increases while the intensity of the $c$-TiAlN decreases. For even higher $\mathrm{T}_{\mathrm{a}}, \sim 1130{ }^{\circ} \mathrm{C}$ for $\mathrm{Ti}_{0.53} \mathrm{Al}_{0.47} \mathrm{~N}$ and $1030{ }^{\circ} \mathrm{C}$ for $\mathrm{Ti}_{0.35} \mathrm{Al}_{0.65} \mathrm{~N}$, diffraction peaks from $h$-AlN are observed.

Figure 6 (a) shows the experimentally observed strain evolution with temperature in the in-plane direction of the $\operatorname{Ti}_{0.53} \mathrm{Al}_{0.47} \mathrm{~N}$ film deposited with low $(20 \mathrm{~V})$ bias. The strain is more or less constant for $\mathrm{T}_{\mathrm{a}}<850{ }^{\circ} \mathrm{C}$. For $\mathrm{T}_{\mathrm{a}}>930^{\circ} \mathrm{C}$, the compressive strain increases in the $c$-TiAlN phase. The TiN formed above $950{ }^{\circ} \mathrm{C}$ is compressively strained in the inplane direction and so is the $h$-AlN as it is formed. Between 1000 and $1100{ }^{\circ} \mathrm{C}$, the diffraction peaks are broad and the difference in position of the $c$-TiAlN and $c$-TiN peak is small, see fig. 5. Thus, the scattering of data within this temperature range is an effect of peak broadening and overlap, giving rise to an uncertainty in determining the correct peak position. Figure 6 (b) shows the scattering domain size from small angle scattering measurements on a $\mathrm{Ti}_{0.53} \mathrm{Al}_{0.47} \mathrm{~N}$ thin film deposited with the same deposition parameters (20 V) taken from ref. [17]. The in-plane diameter of the first detectable domains is 2.4 nm at $\mathrm{T}_{\mathrm{a}}=866{ }^{\circ} \mathrm{C}$ and the domains grow with temperature to reach $8.0 \mathrm{~nm}$ at $\mathrm{T}_{\mathrm{a}}=1011^{\circ} \mathrm{C}$. 


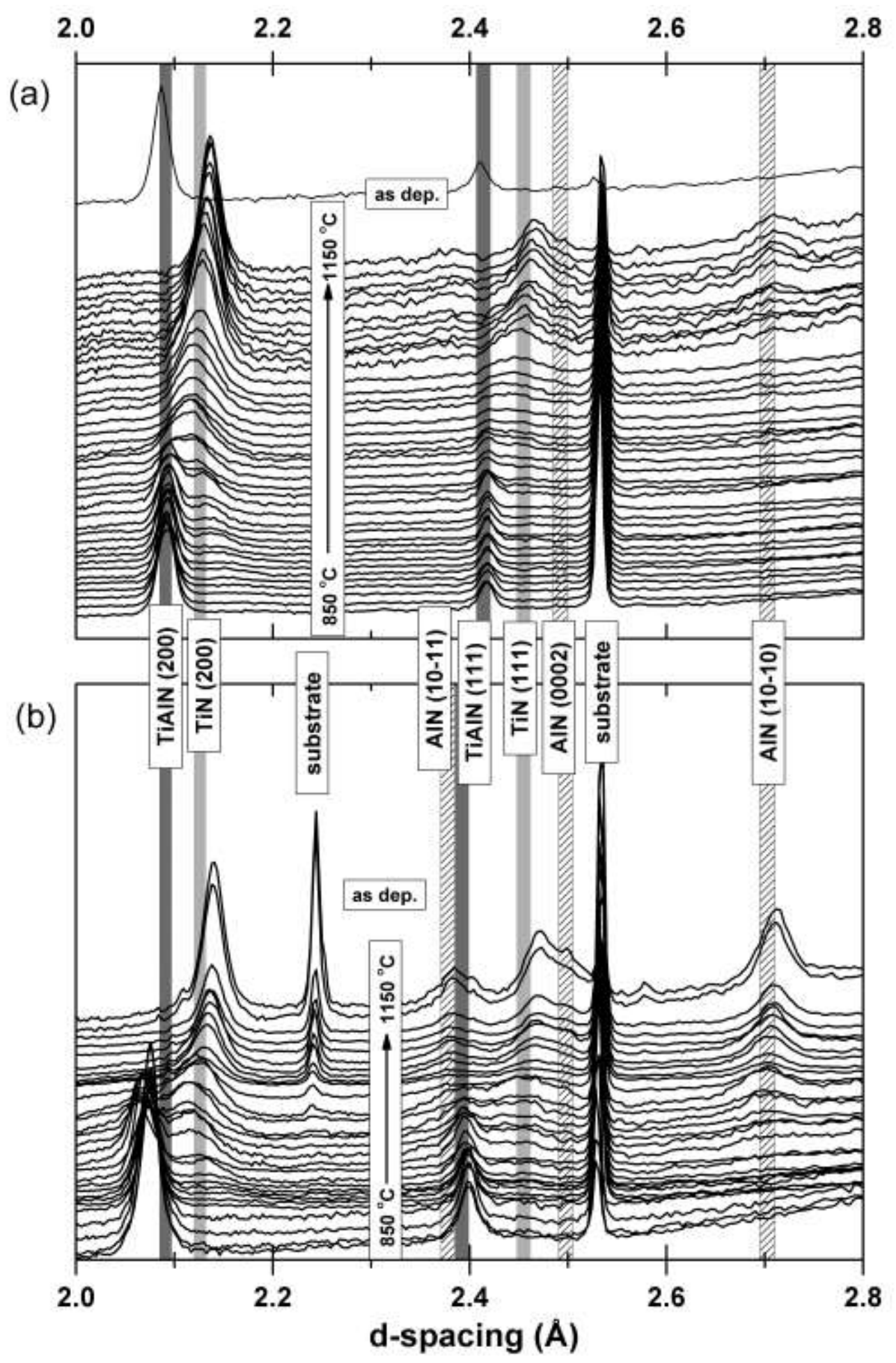

Figure 5: XRD lineouts with temperature increasing from $850{ }^{\circ} \mathrm{C}$ to $1150{ }^{\circ} \mathrm{C}$, with an interval of $\sim 10{ }^{\circ} \mathrm{C}$, for the in-plane direction of (a) $\mathrm{Ti}_{0.53} \mathrm{Al}_{0.47} \mathrm{~N}$ and (b) $\mathrm{Ti}_{0.35} \mathrm{Al}_{0.65} \mathrm{~N}$ thin films. The top diffractogram in (a) and (b) shows the lineout of the as-deposited film. Peaks are labeled showing un-strained lattice spacing for room temperature (lowest d) to $1150{ }^{\circ} \mathrm{C}$ with a coefficient of thermal expansion of $5 \times 10^{-5}{ }^{\circ} \mathrm{C}^{-1}$. 


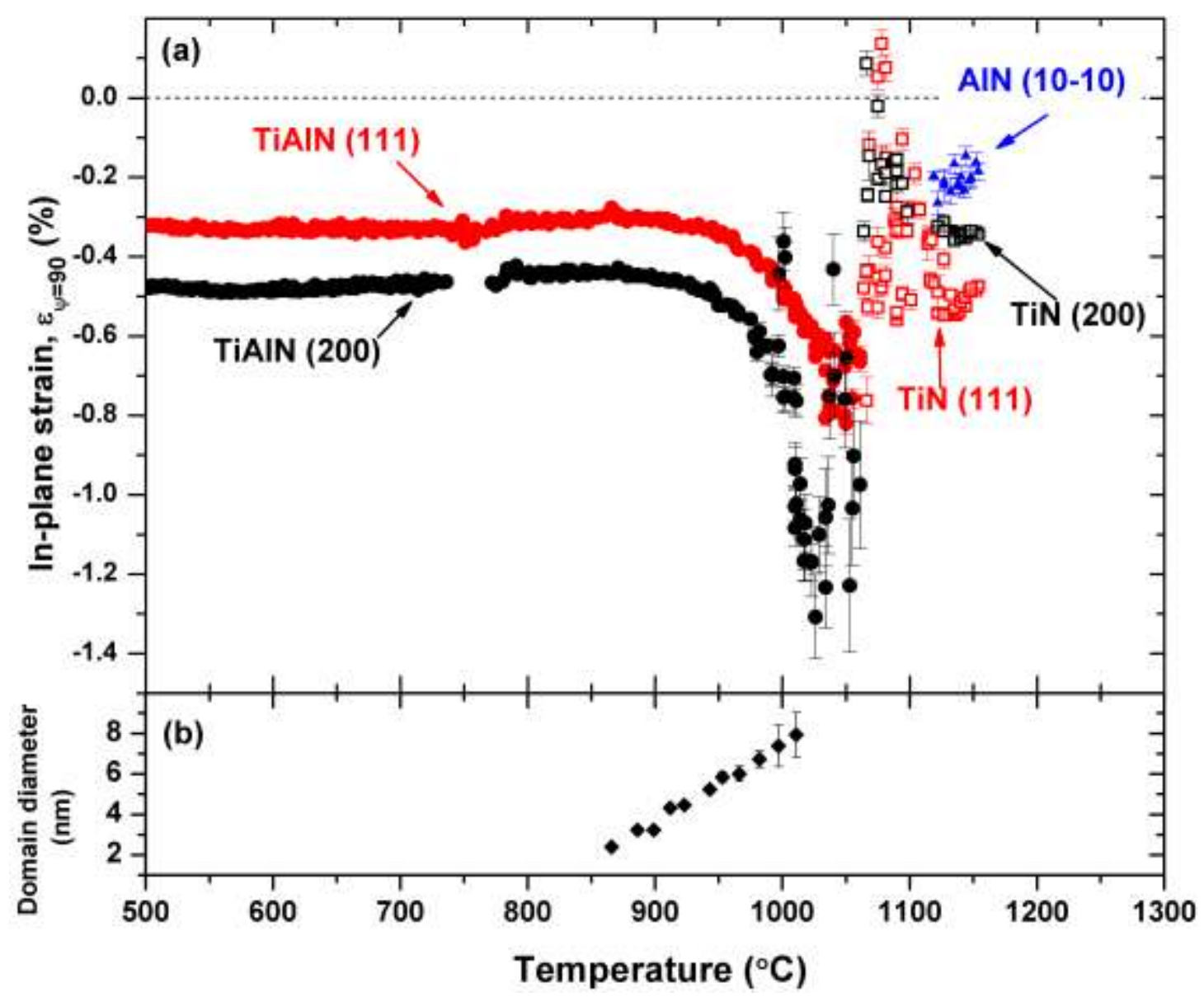

Figure 6: (a) strain in the film in-plane direction for $\operatorname{Ti}_{0.53} \mathrm{Al}_{0.47} \mathrm{~N}$ and deposited with $20 \mathrm{~V}$ bias showing $c$-TiAlN below $1050{ }^{\circ} \mathrm{C}$ (filled circles) and $c$-TiN (open circles) and h-AlN (filled triangles) above $1050{ }^{\circ} \mathrm{C}$ and (b) domain size extracted from small angle scattering data taken from ref. [17] (color online).

In figure 7 (a), the in-plane strain in the [200]-direction is shown for $\operatorname{Ti}_{0.53} \mathrm{Al}_{0.47} \mathrm{~N}$ and $\mathrm{Ti}_{0.35} \mathrm{Al}_{0.65} \mathrm{~N}$ deposited with low bias $(20 \mathrm{~V})$ and $\mathrm{Ti}_{0.35} \mathrm{Al}_{0.65} \mathrm{~N}$ deposited with high bias $(60 \mathrm{~V})$. Comparing the two low bias films, the increase in strain is observed to occur at a lower $\mathrm{T}_{\mathrm{a}}$ for the higher $\mathrm{Al}$ content, at $\sim 850{ }^{\circ} \mathrm{C}$ for $\mathrm{Ti}_{0.35} \mathrm{Al}_{0.65} \mathrm{~N}$ and at $\sim 930{ }^{\circ} \mathrm{C}$ for $\mathrm{Ti}_{0.53} \mathrm{Al}_{0.47} \mathrm{~N}$. The high bias film exhibits a decrease in compressive strain for $\mathrm{T}_{\mathrm{a}}<850{ }^{\circ} \mathrm{C}$ while at higher $\mathrm{T}_{\mathrm{a}}\left(850-950{ }^{\circ} \mathrm{C}\right)$ the strain is almost constant. The TiN phase formed is 
compressively strained with about the same magnitude for both $\operatorname{Ti}_{0.35} \mathrm{Al}_{0.65} \mathrm{~N}$ films while the strain is higher for TiN in the $\mathrm{Ti}_{0.53} \mathrm{Al}_{0.47} \mathrm{~N}$ film.

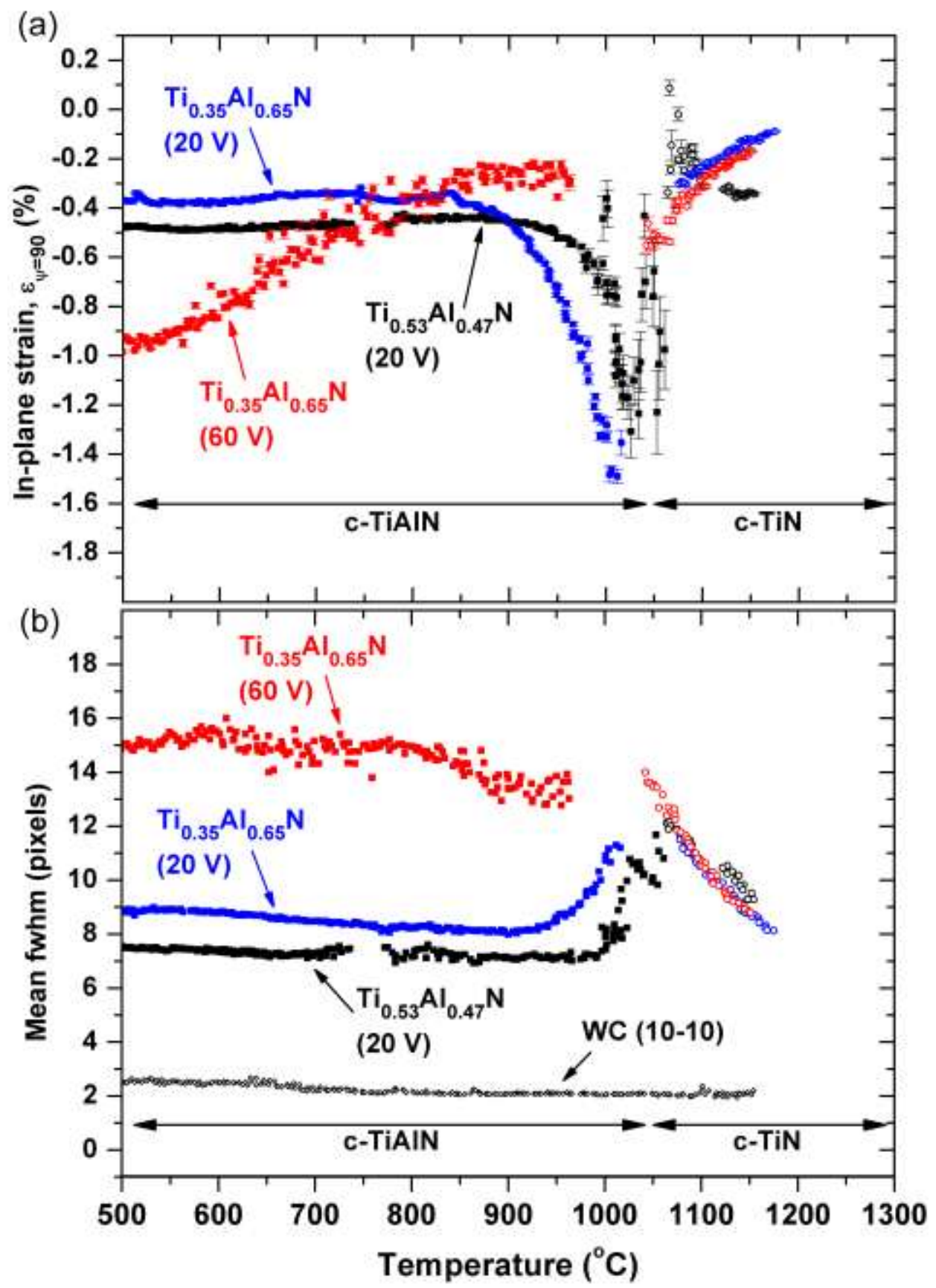

Figure 7: (a) strain in the in-plane direction and (b) orientation averaged peak width extracted from the 200 diffraction line for $\mathrm{Ti}_{0.53} \mathrm{Al}_{0.47} \mathrm{~N}$ and $\mathrm{Ti}_{0.35} \mathrm{Al}_{0.65} \mathrm{~N}(20 \mathrm{~V})$ and $\mathrm{Ti}_{0.35} \mathrm{Al}_{0.65} \mathrm{~N}(60 \mathrm{~V})$ thin films. The strain and fwhm is shown for $c$-TiAlN below $1050{ }^{\circ} \mathrm{C}$ (filled circles) and $c$-TiN above $1050{ }^{\circ} \mathrm{C}$ (open circles). In (b) the fwhm of the WC (1010) diffraction peak is also shown (color online). 
Table 1 lists the strain and stress in the in-plane direction of the films measured at $500{ }^{\circ} \mathrm{C}$, similar to the deposition temperature. The orientation dependent Young's modulus is calculated using the Reuss model and elastic compliances from ab-initio calculations [7]. The Reuss model assumes that the stress and strain is equal for all grains in the sample and has previously been used to describe stresses in thin films [13]. All films exhibits compressive residual stress in the in-plane direction and the stress is higher for the films deposited with higher bias.

Figure 7 (b) shows the orientation averaged peak width of the $c$-TiAlN and $c$-TiN (200) peak. It can be observed that at the deposition temperature for the two low-bias films, the width of the $c$-TiAlN (200) peak is larger for the higher Al content film. The peak width is decreasing slightly with temperature for $\mathrm{T}_{\mathrm{a}}<850{ }^{\circ} \mathrm{C}$ while at higher $\mathrm{T}_{\mathrm{a}}$ the peak width increases. The $c$-TiAlN (200) peak of the film deposited with higher bias shows larger widths at the deposition temperature and the width decreases with $\mathrm{T}_{\mathrm{a}}$. The TiN formed at $\mathrm{T}_{\mathrm{a}}>1000{ }^{\circ} \mathrm{C}$ has similar peak width for all three films and the width is decreasing with temperature. Shown in figure 7 (b) is also the width of the WC (10-10) diffraction peak, which is almost constant and smaller than the film peaks for all temperatures, and provides an effective instrumental reference width.

Figure 8 shows the change in peak width with temperature for the in-plane and growth direction of the $\operatorname{Ti}_{0.53} \mathrm{Al}_{0.47} \mathrm{~N}$ film. Initially the $c$-TiAlN peaks are slightly wider in the film in-plane direction. At $\mathrm{T}_{\mathrm{a}}>950^{\circ} \mathrm{C}$, the peak width increases and the increase is larger in the in-plane direction than in the growth direction. The $c$-TiN phase formed above $1000{ }^{\circ} \mathrm{C}$ also shows larger peak width in the in-plane direction of the film. As the 
temperature is increased further, the width of the peaks decreases and at $\mathrm{T}_{\mathrm{a}}>1125{ }^{\circ} \mathrm{C}$ there is no difference between in-plane and growth direction.

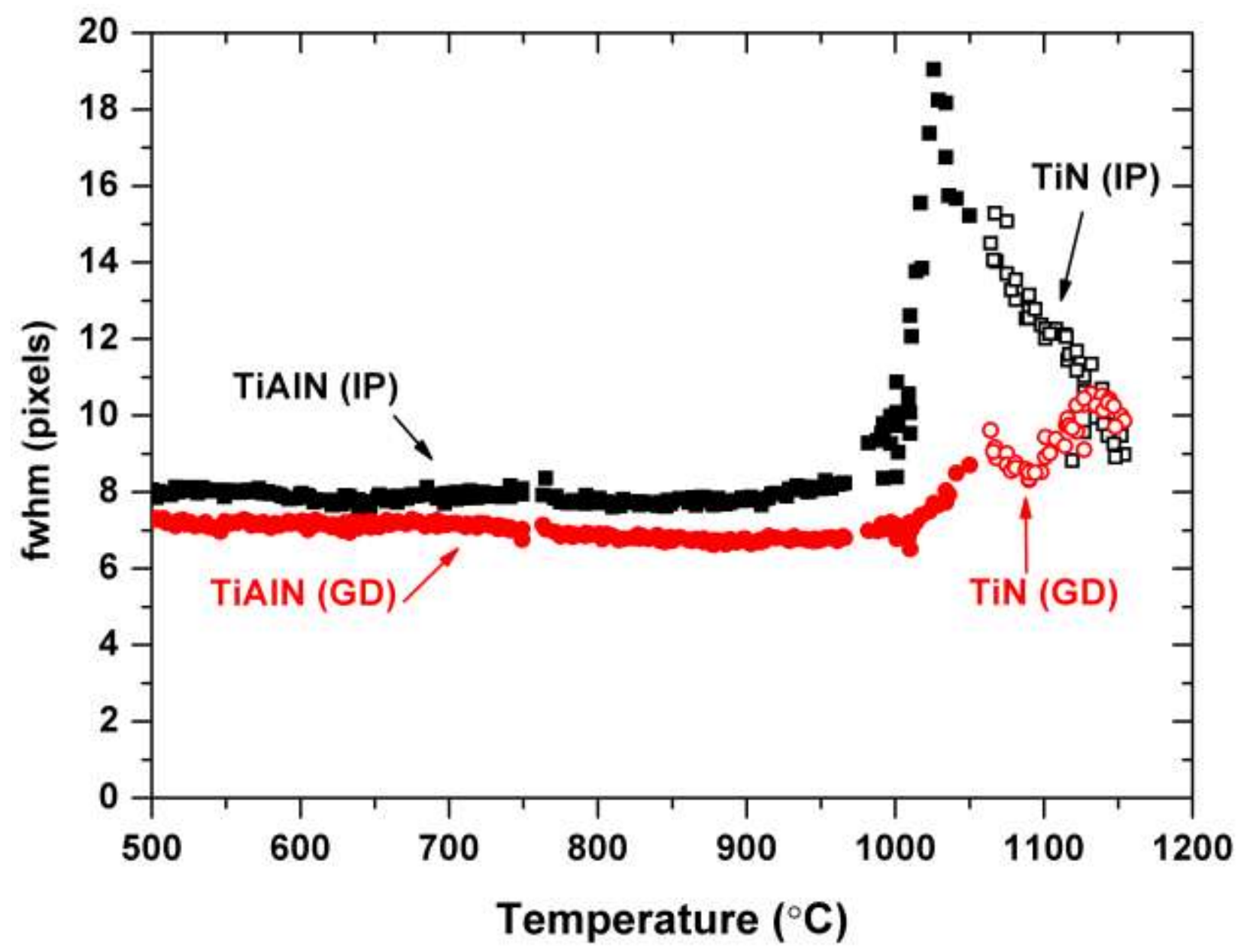

Figure 8: Peak width extracted from the 200 diffraction line in the in-plane and growth direction for the $\mathrm{Ti}_{0.53} \mathrm{Al}_{0.47} \mathrm{~N}(20 \mathrm{~V})$ thin film for $c$-TiAlN below $1050{ }^{\circ} \mathrm{C}$ (filled squares) and $c$-TiN above $1050{ }^{\circ} \mathrm{C}$ (open squares) (color online).

Figure 9 (a) and (b) show the simulated microstructure evolution of $\mathrm{Ti}_{0.50} \mathrm{Al}_{0.50} \mathrm{~N}$ and $\mathrm{Ti}_{0.33} \mathrm{Al}_{0.67} \mathrm{~N}$ viewed in the [00-1]-direction, where white is $\mathrm{AlN}$ and black is TiN. With increasing time at $900{ }^{\circ} \mathrm{C}$, separation into $\mathrm{AlN}$ and $\mathrm{TiN}$ domains begins, after $25 \mathrm{~s}$ in $\mathrm{Ti}_{0.50} \mathrm{Al}_{0.50} \mathrm{~N}$ and after $5 \mathrm{~s}$ in $\mathrm{Ti}_{0.33} \mathrm{Al}_{0.67} \mathrm{~N}$. The microstructure that evolves during 
decomposition is observed to differ for the two compositions with more elongated domains for the higher $\mathrm{Al}$ content.
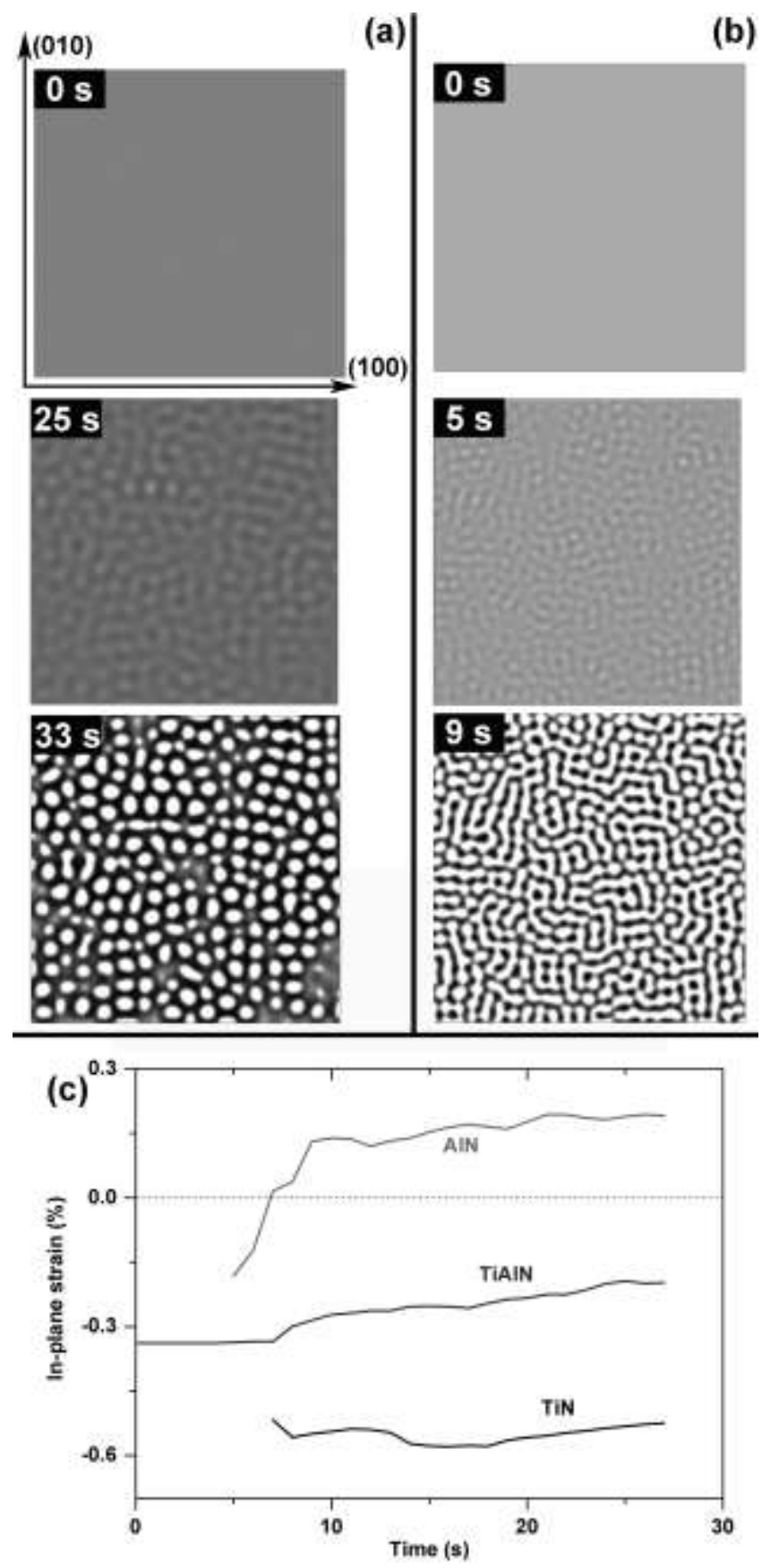

Figure 9: Simulated microstructure, (a) and (b), and strain, (c), evolution of $\mathrm{Ti}_{0.50} \mathrm{Al}_{0.50} \mathrm{~N}$ and $\mathrm{Ti}_{0.33} \mathrm{Al}_{0.67} \mathrm{~N}$. In (a) and (b) the microstructure of $\mathrm{Ti}_{0.50} \mathrm{Al}_{0.50} \mathrm{~N}$ and $\mathrm{Ti}_{0.33} \mathrm{Al}_{0.67} \mathrm{~N}$ is shown for three time steps, respectively, showing AlN domains in white and TiN domains in black. In (c) the strain evolution in the [100] (in-plane) direction of $\mathrm{Ti}_{0.33} \mathrm{Al}_{0.67} \mathrm{~N}$ is shown as a function of time. 
Figure 9 (c) shows the strain evolution in the [100] (in-plane) direction during decomposition of $\mathrm{Ti}_{0.33} \mathrm{Al}_{0.67} \mathrm{~N}$. The strain in the TiAlN phase is constant before the decomposition starts at the value set by the boundary conditions, see table 1. A small decrease in compressive strain can be observed as the decomposition begins. The TiN phase is compressively strained as it is formed. The AlN phase also shows compressive strains as decomposition begins, after which it decreases and is stabilized at a small tensile strain.

\section{Discussion}

\section{$\underline{5.1 \text { Structure and strain of as-deposited films }}$}

The lattice parameter as determined from powder diffraction, fig. 2, agrees well with $a b$ initio calculations of $c$-TiAlN $[5,12]$ suggesting that the films consist of a well mixed solid solution. The calculations are known to overestimate the lattice parameter, leading to the observed trend relative to experimental results shown in the figure [12].

All films studied here have compressive strain in the in-plane direction as is commonly observed for arc-evaporated films, and primarily attributed to defects created during deposition [18-20]. Strains in thin films can have several origins [18]. Incorporated impurities, misplaced atoms and other defects created during growth results in compressive strains [20-23]. Thermal strains arise from differences in thermal expansion coefficient between film and substrate or between different phases in the film if the measurement is performed at another temperature than the deposition temperature $[18$, 
24]. The presence of two or more phases can result in epitaxial misfit strains [25]. Further, phase transformations in the film after growth can cause additional strains [18, 26, 27].

The average of strain over all grains in the sample is usually referred to as the macrostrain and is observed as a shift of the diffraction peak from its un-strained position. The strain and stress reported in table 1 is measured at the deposition temperature where the thermally induced strain should be minimized. As the films are single phase in this case, the measured strains are most likely due to defects in the film. The magnitude of stress in the as-deposited films is observed to depend on composition as well as on deposition parameters, see table 1. For films of the same composition, increasing the bias during deposition increases the stress of the as-deposited film. The low temperature and substrate bias used here will limit the surface diffusion during deposition, while higher bias can increase the atom mobility and lead to defect annihilation during growth [21]. The higher bias $(60 \mathrm{~V})$ increases the ion bombardment and thus the defect density as the atom mobility in this case is still too low for defect annihilation to take place.

Comparing the two low-bias films the highest macrostrain at the deposition temperature is obtained for the film with 50 at.\% Al, fig 7 (a). The energy of the ions arriving at the substrate during deposition depends on the ion charge state and the substrate bias [23]. Using the cathode with higher $\mathrm{Ti}$ content $\left(\mathrm{Ti}_{0.50} \mathrm{Al}_{0.50}\right)$ the amount of heavy Ti ions increases compared to the $\mathrm{Ti}_{0.33} \mathrm{Al}_{0.67}$ cathode. Ti ions further have a higher mean charge state than $\mathrm{Al}[28]$ and thus the increased ion energy gives rise to more defects in the $\mathrm{Ti}_{0.53} \mathrm{Al}_{0.47} \mathrm{~N}$ film.

The TiAlN phase shows larger strains along [200] directions than the [111] directions, fig. 6, which is in accord with the elastic anisotropy calculated by Tasnadi et al. [7]. The 
elastic anisotropy also varies with composition and is larger for the higher $\mathrm{Al}$ content (not shown), which is also expected based on the calculations. For TiN detected above $950{ }^{\circ} \mathrm{C}$, the strains are larger along [111] directions.

Broadening of the diffraction peak is due to variations in strain (or equivalently lattice spacing) within and/or between grains, and is commonly referred to as microstrain. Broadening can also be caused by small grain sizes, in addition to local variations in composition. Due to the large grain size and small strain $(\sim 0.008 \%)$ in the substrate, the width of the WC peak is mainly due to instrumental broadening and thus gives a minimum value of the peak width (instrumental contribution). For all annealing temperatures, the width of the film peaks is larger than that of the substrate. The coating grains are on the order of $100 \mathrm{~nm}$, as observed in fig. 3 (a), and at this level should only weakly contribute to peak broadening. As observed in fig. 8, the peak width of the asdeposited film is slightly larger in the in-plane than growth direction. This is due to the elongated columnar structure in the growth direction. The peak width is larger for the higher $\mathrm{Al}$ content film, fig. 7 (b). As the macrostrain of this film is smaller than for the $\mathrm{Ti}_{0.53} \mathrm{Al}_{0.47} \mathrm{~N}$ film the increased peak width is not likely to be caused by defects. Instead the increased peak broadening can come from compositional fluctuations arising during deposition or a smaller grain size in this film. Higher substrate bias during deposition also increases the microstrain due to the increased number of defects, fig. 7 (b), which was also observed for the macrostrain, fig. 7 (a). 


\section{$\underline{5.2 \text { Microstructure evolution }}$}

The phase decomposition is initiated at a temperature of $\sim 1000{ }^{\circ} \mathrm{C}$ (see fig. 3) which has also been observed in e.g., refs. [1-3]. The DSC results in fig. 4 reveals an exothermic reaction between 900 and $1100{ }^{\circ} \mathrm{C}$, which has been interpreted as the formation of nmsized domains with either TiN or AlN enrichment $[2,29]$. The lower heating rate of the in-situ x-ray diffraction experiments would cause the reaction to take place at lower temperature compared to the DSC data. Compared to the particle size as determined by small angle x-ray scattering (SAXS), see fig. 6 and ref. [17], the decomposition has started already at $850^{\circ} \mathrm{C}$, which is lower than the temperature at which we observe TiN here. At this temperature $\left(850^{\circ} \mathrm{C}\right)$, however, the difference in $\mathrm{Al}$ content between the domains is still small, wherefore no diffraction peaks from $c$-TiN or $c$-AlN are observed. When diffraction from $c$-TiN is detected at $950{ }^{\circ} \mathrm{C}$ the domain size is of the order of $6 \mathrm{~nm}$ in diameter for $\mathrm{Ti}_{0.53} \mathrm{Al}_{0.47} \mathrm{~N}$ as shown by the SAXS results, see fig. 6 and ref [17]. No $c$ AlN peaks can be observed in the lineouts. The domains has been shown to have similar size [3] but the lower electron density of $c$-AlN compared to $c$-TiN results in a lower xray scattering yield of $c$-AlN thus the diffraction peaks of this phase are not observed.

The simulations show that the elastic anisotropy affects the evolved microstructure, where the higher anisotropy of the higher Al content film gives domains elongated in the [100]-direction, fig. 9. The width of the $c$-TiN diffraction peaks is initially larger in the film in-plane direction, indicating smaller coherent scattering domains in this direction and thus TiN domains that are elongated in the growth direction. The presence of compressive strain in the in-plane direction will make it energetically favorable for the domains to form perpendicular to this direction. Further, the presence of columnar 
boundaries can favor diffusion in the growth direction. As the $c$-TiN domains grow, the difference in peak width in in-plane and growth direction disappears as the domains become more equiaxed, see fig. 8 .

\section{$\underline{5.3 \text { Strain evolution }}$}

During annealing, several factors will influence the strain of the films. The coefficient of thermal expansion (CTE) is not known for TiAlN. If assumed to be similar to the CTE of $c$-TiN, the higher CTE of the film $\left(9.5 \times 10^{-6}{ }^{\circ} \mathrm{C}^{-1}[30]\right)$ than the substrate $\left(\sim 5 \times 10^{-6}{ }^{\circ} \mathrm{C}^{-1}\right.$ [31]) will result in compressive strains during annealing at temperatures above the deposition temperature. Commonly for arc-evaporated films, defect annihilation and stress relaxation take place during annealing at temperatures above the deposition temperature [32]. In addition to these two contributions, the decomposition of $c$-TiAlN will affect the stress state.

The first exothermic peak, T1, in the heat flow curve, fig. 4, has previously been assigned to defect annihilation and crystal recovery $[2,3]$. Defect annihilation would result in a decrease in compressive strain which is not observed in the temperature region suggested by DSC results for the low-bias films, see fig. 7 (a). The difference in CTE is expected to induce increased compressive strains with temperature, which also is not observed. In the higher bias film, which has a larger initial stress state, the strain decreases with annealing temperature. Thus, in the low-bias films the simultaneous effects of thermal strains and defect annihilation makes it difficult to separate the effects, while the larger relaxation in the high-bias films is observed. 
A decrease in peak width, corresponding to a decrease in microstrain, is observed between the deposition temperature and $900{ }^{\circ} \mathrm{C}$ for the low-bias films, fig 7(b), indicating defect annihilation and crystal recovery. For the high-bias film, the peak width decreases above $800{ }^{\circ} \mathrm{C}$, suggesting that defect annihilation is ongoing at higher temperatures in this case. Defects resulting from high-energy ion bombardment during deposition are more stable than defects created when the ion energy is low [32, 33]. Also the DSC results from the high-bias film indicate that defect annihilation is present at higher temperatures observed as an apparent larger size of the T2 and T3 peaks due to overlap of an exothermic peak arising from defect annihilation.

The simulations only show the effect of spinodal decomposition on the strain evolution, with no consideration taken to thermal expansion or defect annihilation. Neither the effect of nitrogen diffusion nor the possible existence of $h$-AlN is considered. Further, the simulations do not take the effect of grain boundaries into account. Therefore, comparison between the simulations and the experimental results will enable to separate the effect of spinodal decomposition from other effects that influences the strain evolution.

During decomposition, the formation of $c$-TiN and $c$-AlN will decrease the molar volume due to the deviation in lattice parameter from Vegard's law, see fig. 2. As the film is constrained by the substrate, it will not be able to decrease its volume and tensile strains form. This is observed in the simulation results as a decrease in compressive strain in the TiAlN domains, see fig. 9. Formation of tensile strains during decomposition has also been observed experimentally for $\mathrm{Ti}_{0.50} \mathrm{Al}_{0.50} \mathrm{~N}$ thin films [27]. As was discussed in the previous section, the decomposition is expected to begin already before $950{ }^{\circ} \mathrm{C}$ for 
$\mathrm{Ti}_{0.53} \mathrm{Al}_{0.47} \mathrm{~N}$ as suggested by SAXS and DSC results. The small decrease in strain expected directly when segregation begins is not observed experimentally, perhaps due to its small magnitude in combination with other factors affecting the strain state.

For both the low-bias films, a large increase in compressive strain is observed as the decomposition is initiated which cannot be explained by the spinodal decomposition or the defect annihilation. Also for the thermal strains, the increase is expected to be more or less linear with annealing temperature. Compressive stresses can be expected to form as $h$-AlN forms due to its large molar volume compared to TiAlN. No diffraction peaks from $h$-AlN can be observed at temperatures lower than $1030{ }^{\circ} \mathrm{C}$ and $1130{ }^{\circ} \mathrm{C}$ for the low- and high-Al content films, respectively, see fig. 5. Nucleation of $h$-AlN is expected to take place within $c$-AlN rich domains. The size of these $c$-AlN rich domains is $\sim 4 \mathrm{~nm}$ at $900{ }^{\circ} \mathrm{C}$, see fig. 6 and ref. [17], which has also previously been observed [3, 17]. $h$-AlN domains, as they form, would have to be smaller than this and thus, possible $h$-AlN domains will at this stage be too small to be observed by XRD. Considering the large difference in molar volume between $h$-AlN $\left(\mathrm{V}_{\mathrm{m}}(h\right.$-AlN $\left.)=1.27 \times 10^{-5} \mathrm{~m}^{3}[2]\right)$ and all the cubic phases $\left(\mathrm{V}_{\mathrm{m}}(\mathrm{TiN})=1.15 \times 10^{-5} \mathrm{~m}^{3}\right.$ [34] and $\mathrm{V}_{\mathrm{m}}\left(\mathrm{Ti}_{0.33} \mathrm{Al}_{0.67} \mathrm{~N}\right)=1.076 \times 10^{-5} \mathrm{~m}^{3}$, see section 3) even small amount of $h$-AlN could influence the strain substantially. Rafaja et al. [35] observed that for a two-phase mixture of hexagonal and cubic phases in high Al content TiAlN the lattice strains were increased compared to a single phase film. Grains of $c$-TiAlN and $h$-AlN were found to be partially coherent as observed also in [36], giving rise to coherency strains. They further found that the hardness of the high strained two-phase films was increased compared to films with only incoherent grains [35]. Also 
Rachbauer et al. [37] found that formation of $h$-AlN in the grain boundaries during annealing of TiAlN thin films increased the microstrain in the $c$-TiAlN phase.

The temperature range of increased compressive strain is comparable to where the maximum hardness of TiAlN films has been observed [2, 29, 38]. This age hardening has been attributed to the formation of coherency strains between cubic domains of different $\mathrm{Al}$ content. The results here show that also the initial formation of $h$-AlN could contribute to the increased strain and thus to an increased hardness.

The simulations show that the decomposition is initiated faster for higher Al contents. The higher Al content film has a larger driving force for decomposition due to the nonsymmetric miscibility gap which is higher at $\mathrm{x}=0.67$ than at $\mathrm{x}=0.50$ [10]. The DSC results here, also suggest that the decomposition begins at a lower temperature for the higher $\mathrm{Al}$ content film. The increase in strain occurs at lower temperatures for the higher Al content, fig. 7 (a), while the appearance of diffraction peaks from TiN occurs at about the same temperature for both compositions. If the decomposition begins at a lower temperature in the higher $\mathrm{Al}$ content film, as predicted by the simulations, $h$-AlN domains could form earlier in this film, which would cause an earlier increase in compressive strain in this case.

As $c$-TiN and $c$-AIN form, they will be strained by the remaining TiAlN matrix. $c$-TiN has a larger molar volume than the matrix, wherefore this phase has compressive strains as observed in the results from the simulations, fig. 9 (c). Also from the experimental results, the $c$-TiN has compressive strains as it is formed, fig. 7 (b). The simulations show a change from compressive to tensile strains in the $c$-AlN phase during decomposition. This is an effect of the change in TiN-content within the interval which the strain is 
summed over (80-100 \% AlN). As the amount of TiN within the composition interval decreases the strain becomes tensile due to the smaller molar volume of $c$-AlN compared to $c$-TiAlN.

\section{Conclusions}

The strain and microstructure evolution during decomposition of $c$-TiAlN thin films have been studied using a combination of in-situ x-ray scattering and phase-field simulations. The simulations predict that the composition affects both the microstructure evolution and the rate of decomposition. The higher elastic anisotropy of the $\operatorname{Ti}_{0.35} \mathrm{Al}_{0.65} \mathrm{~N}$ film results in formation of elongated TiN and AlN domains during decomposition. The experimental results show that also in the $\mathrm{Ti}_{0.53} \mathrm{Al}_{0.47} \mathrm{~N}$ film, the TiN domains formed are elongated in the growth direction. Experimental findings show that the decomposition is initiated earlier in the $\mathrm{Ti}_{0.35} \mathrm{Al}_{0.65} \mathrm{~N}$ film which is confirmed by the simulations.

The decomposition gives rise to strains in the film as shown by the simulations. The experimental results also show additional formation of compressive strain during decomposition, that is not related to the spinodal decomposition. Instead the results suggest that small domains of $h$-AlN are formed already in the early stages of decomposition causing an increase in strain.

\section{$\underline{\text { Acknowledgement }}$}

The authors acknowledge financial support from the VINNEX Center of Excellence on

Functional Nanoscale Materials (FunMat).), the Swedish Foundation for Strategic Research under the program Designed Multicomponent Coatings (Multifilms), and the 
Swedish Research Council. Axel Knutsson and Niklas Norrby from Linköping University assisted with DSC and TEM work, respectively.

The use of the Advanced Photon Source was supported by the U. S. Department of Energy, Office of Science, Office of Basic Energy Sciences under contract No. DEAC02-06CH11357 


\section{References}

[1] A. Hörling, L. Hultman, M. Odén, J. Sjölén, L. Karlsson, J. Vac. Sci. Technol. A 20 (2002) 1815.

[2] P.H. Mayrhofer, A. Hörling, L. Karlsson, C. Mitterer, L. Hultman, Appl. Phys. Lett. 83 (2003) 2049.

[3] A. Knutsson, M.P. Johansson, P.O.Å. Persson, L. Hultman, M. Odén, Appl. Phys. Lett. 93 (2008) 143110.

[4] P.H. Mayrhofer, D. Music, J.M. Schneider, Appl. Phys. Lett. 88 (2006) 071922.

[5] B. Alling, A.V. Ruban, A. Karimi, O.E. Peil, S.I. Simak, L. Hultman, I.A. Abrikosov, Phys. Rev. B 75 (2007) 045123.

[6] J.S. Koehler, Phys. Rev. B 2 (1970) 547.

[7] F. Tasnádi, I.A. Abrikosov, L. Rogström, J. Almer, M.P. Johansson, M. Odén, Appl. Phys. Lett. 97 (2010) 231902.

[8] J.W. Cahn, Acta Metall. 9 (1961) 795.

[9] D.J. Seol, S.Y. Hu, Y.L. Li, J. Shen, K.H. Oh, L.Q. Chen, Acta Mater. 51 (2003) 5173.

[10] B. Alling, A.V. Ruban, A. Karimi, L. Hultman, I.A. Abrikosov, Phys. Rev. B 83 (2011) 104203.

[11] J.W. Cahn, J.E. Hilliard, J. Chem. Phys. 28 (1958) 258.

[12] B. Alling, A. Karimi, I.A. Abrikosov, Surf. Coat. Technol. 203 (2008) 883.

[13] J. Almer, U. Lienert, R.L. Peng, C. Schlauer, M. Odén, J. Appl. Phys. 94 (2003) 697.

[14] Flex PDE 6, V 6.16. PDE Solutions Inc., 2011.

[15] A.O. Eriksson, J.Q. Zhu, N. Ghafoor, M.P. Johansson, J. Sjölén, J. Jensen, M. Odén, L. Hultman, J. Rosén, Surf. Coat. Technol. 205 (2011) 3923.

[16] P.H. Mayrhofer, D. Music, J.M. Schneider, J. Appl. Phys. 100 (2006).

[17] M. Odén, L. Rogström, A. Knutsson, M.R. Terner, P. Hedström, J. Almer, J. Ilavsky, Appl. Phys. Lett. 94 (2009).

[18] H. Oettel, R. Wiedemann, S. Preißler, Surf. Coat. Technol. 74-75 (1995) 273.

[19] L. Karlsson, L. Hultman, M.P. Johansson, J.E. Sundgren, H. Ljungcrantz, Surf. Coat. Technol. 126 (2000) 1.

[20] J. Almer, M. Odén, G. Håkansson, Thin Solid Films 385 (2001) 190.

[21] H. Ljungcrantz, L. Hultman, J.E. Sundgren, L. Karlsson, J. Appl. Phys. 78 (1995)

832.

[22] P.H. Mayrhofer, C. Mitterer, L. Hultman, H. Clemens, Prog. Mater. Sci. 51 (2006) 1032.

[23] A. Anders. Cathodic Arcs, From Fractal Spots to Energetic Condensation: Springer Series, 2008.

[24] I.C. Noyan, T.C. Huang, B.R. York, Crit. Rev. Solid State Mater. Sci. 20 (1995) 125.

[25] M. Birkholtz. Thin Film Analysis by X-ray Scattering: Wiley-VCH Verlag GmbH \& Co, 2006.

[26] M. Bartosik, R. Daniel, C. Mitterer, J. Keckes, Surf. Coat. Technol. 205 (2010) 1320. 
[27] D. Rafaja, C. Wüstefeld, C. Baehtz, V. Klemm, M. Dopita, M. Motylenko, C. Michotte, M. Kathrein, Metall. Mater. Trans. A (2011) 1.

[28] A. Anders, Phys. Rev. E 55 (1997) 969.

[29] A. Knutsson, M.P. Johansson, L. Karlsson, M. Oden, J. Appl. Phys. 108 (2010) 044312.

[30] L.E. Toth. Transition Metal Carbides and Nitrides. New York: Academic Press, 1971.

[31] B. Uhrenius, Int. J. Refr. Metal. Hard Mat. 12 (1994) 121.

[32] L. Karlsson, A. Hörling, M.P. Johansson, L. Hultman, G. Ramanath, Acta Mater. 50 (2002) 5103.

[33] P.H. Mayrhofer, C. Mitterer, Surf. Coat. Technol. 133-134 (2000) 131.

[34] PDF No. 38-1420, JCPDS - International Centre for Diffraction Data, 1998.

[35] D. Rafaja, A. Poklad, V. Klemm, G. Schreiber, D. Heger, M. Síma, M. Dopita, Thin Solid Films 514 (2006) 240.

[36] U. Wahlström, L. Hultman, J.E. Sundgren, F. Adibi, I. Petrov, J.E. Greene, Thin Solid Films 235 (1993) 62.

[37] R. Rachbauer, S. Massl, E. Stergar, D. Holec, D. Kiener, J. Keckes, J. Patscheider, M. Stiefel, H. Leitner, P.H. Mayrhofer, J. Appl. Phys. 110 (2011) 023515.

[38] A. Hörling, L. Hultman, M. Odén, J. Sjölén, L. Karlsson, Surf. Coat. Technol. 191 (2005) 384. 